23. Shepherd, A.: Intestinal $\mathrm{O}_{2}$ consumption and ${ }^{86} \mathrm{Rb}$ extraction during arterial hypoxia. Am. J. Physiol., 234: E248 (1978).

24. Shepherd, A.: Role of capillary recruitment on the regulation of intestinal oxygenation. Am. J. Physiol., 242: G435 (1982).

25. Shepherd. A.: Effect of arterial pulse pressure and hypoxia on myogenic responses in the gut. Am. J. Physiol., 235: H157 (1978).

26. Shepherd, A., Pawlik, W., Mailman, D., Burks, T., and Jacobsen, E.: Effect of vasoconstrictors on intestinal vascular resistance and oxygen extraction. Am. J. Physiol., 230: 298 (1976).

27. Siregar, H. and Chou, C.: Relative contribution of fat, protein, carbohydrate, and ethanol to intestinal hyperemia. Am. J. Physiol., 242: G27 (1982).

28. Svanik, J.: Mucosal hemodynamics in the small intestine of the cat during regional sympathetic vasoconstrictor activation. Acta Physiol. Scand., 89: 19 (1973).

29. Svanik, J., Tyllstrom, J., and Wallentin, I.: The effects of hyperemia and hypoxia on the distribution of capillary blood flow in the denervated intestinal vascular bed. Acta Physiol. Scand., 74: 543 (1968).

30. Vatner, S. Higgens, C.. and Franklin, D.: Regional circulatory adjustments to moderate and severe chronic anemia in conscious dogs at rest and during exercise. Circ. Res.. 30: 731 (1972).

31. Wallenstein. S. Zucker, C., and Fleiss, J.: Some statistical methods useful in circulation research. Circ. Res., 47: 1 (1980)

32. Recipient of Basil O'Connor Starter Research Grant (\#5-256) from the March of Dimes Birth Defect Foundation.

33. The authors thank Mr. Raymond Petit for his skillful technical assistance; Albert S. Most, MD. FACC. Physician in Charge, Division of Cardiology and the staff of the Cardiovascular Research Laboratory, Rhode Island Hospital, for their assistance and cooperation; and Ms. Brenda Swanson for her secretarial assistance.

34. Requests for reprints should be addressed to: William Oh, MD, 50 Maude Street, Providence, RI 02908

35. This research was supported by National Research Service Award \#I T32 HD07232-01.

36. Received for publication October 22, 1982.

37. Accepted for publication July 14, 1983.

\title{
Relative Efficacy of Radiant and Convective Heat in Incubators in Producing Thermoneutrality for the Premature
}

\author{
MICHAEL H. LEBLANC ${ }^{(27)}$ \\ University of Cincinnati College of Medicine and The Children's Hospital Research Foundation, \\ Cincinnati, Ohio, USA
}

\section{Summary}

To determine which warming system more closely approximates a neutral thermal environment, the oxygen consumptions of 16 premature babies $<1500 \mathrm{~g}$ were measured in a convectively heated incubator and a radiantly heated incubator. Both systems were controlled to maintain a skin temperature of $36^{\circ} \mathrm{C}$. The oxygen consumptions of the infants were not significantly different in the two incubators; thus, there was no detectable advantage to the use of convective or radiant energy in approximating a neutral thermal environment in an incubator for the small premature infant. That proportion of total heat loss from the babies due to radiant losses in the convective incubator was directly calculated from incubator temperature using equations described in the paper, and found to be $68 \pm 3 \% \mathrm{SE}$.

A neutral thermal environment is an environment in which standard metabolic rate, or oxygen consumption, is minimal, and within which temperature regulation is achieved by nonevaporative physical processes alone (2). Because the neutral thermal range (21) seems to coincide with the conditions under which premature babies show the greatest survival rate $(4,7)$, it has been theorized that the best incubator or warmer would be one which maintained the infant in a neutral thermal environment: a state of minimal oxygen consumption.

The survival rate studies by Day et al. (7) and Buetow and Klein (4) showed that the highest survival rate was achieved in a warm radiantly heated incubator. Because this radiantly heated incubator is no longer manufactured, most nurseries use convectively heated incubators or open radiant warmers. Equally warm radiantly and convectively heated enclosed incubators have never been compared, either for survival rate or for thermoneutrality. But it was demonstrated in our laboratory that the open radiant warmer is less thermoneutral for the small premature than a convectively heated incubator (12). The radiant incubator, in contrast to the open radiant warmer, has a more consistent air flow pattern as it is enclosed rather than open. It has a warmer air temperature and, thus, less difference between effective radiant and convective temperature. The relative inferiority of the thermal environment produced by an open radiant warmer may or may not be due to the use of radiant energy as a heat source. It seemed appropriate, therefore, to compare infants' oxygen consumptions in a radiantly heated incubator and a convectively heated incubator.

\section{MATERIALS AND METHODS}

Sixteen infants under $1500 \mathrm{~g}$ were studied. The 16 infants were feeding and gaining weight at the time of the study and required no supplemental oxygen. Informed consent was obtained. A summary of the characteristics of the infants is given in Table 1.

Each infant was studied both in the radiantly heated incubator and the convectively heated incubator. The order in which the incubators were used was randomized. The infant's oxygen consumption was measured during a period of non-REM sleep after the infant equilibrated at least $1 \mathrm{~h}$ in each of the incubators. Non-REM sleep was defined as a period of $20 \mathrm{~min}$ of apparent sleep with a period of at least 10 min of regular respirations, no rapid eye movements (by observation through closed lids), and no gross movements except occasional jerks. All oxygen con- 
Table 1. Infant characteristics

\begin{tabular}{lcc}
\hline & Mean \pm S.D. & Range \\
\hline Gestational age & $31.1 \pm 2.1 \mathrm{wk}$ & $26-35 \mathrm{wk}$ \\
Birth weight & $1212 \pm 260 \mathrm{~g}$ & $750-1595 \mathrm{~g}$ \\
Age & $22 \pm 13 \mathrm{~d}$ & $6-49 \mathrm{~d}$ \\
Postconceptional age & $34 \pm 2.3 \mathrm{wk}$ & $29-40 \mathrm{wk}$ \\
Weight at experiment & $1344 \pm 148 \mathrm{~g}$ & $1000-1490 \mathrm{~g}$ \\
& & no./no. \\
SGA/AGA* & & $5 / 11$ \\
Male/Female & & $10 / 6$ \\
\hline
\end{tabular}

* SGA/AGA, small for gestational age/average for gestational age.

sumption measurements were deferred until at least $1 / 2 \mathrm{~h}$ after feedings or other interventions associated with the infant's care. After a measurement that met all these conditions, the infant was switched to the other incubator or, on termination of the experiment, returned to his usual mode of care.

The radiantly heated incubator was an Air-Shields Model C86 incubator with the convective heater turned off and the heat provided by a Merco Products radiant heater, Model SH-36-SS, suspended from the incubator shelf $17 \mathrm{~cm}$ above the top wall of the incubator. The Merco warmer was turned on and off by a signal from a PDP-11 computer as described previously $(1,17)$. The heater was regulated so as to maintain the sum of the skin and the environmental temperatures $\left(T_{e}\right.$, arbitrarily defined) equal to a set point, i.e.,

$$
\begin{gathered}
\mathrm{T}_{\text {set point }}=\mathrm{T}_{\text {skin }}+\mathrm{T}_{\mathrm{c}} \\
\mathrm{T}_{\mathrm{c}}=0.63 \mathrm{~T}_{\text {Air }}+0.25 \mathrm{~T}_{\text {front wall }}+0.12 \mathrm{~T}_{\text {top wall }}
\end{gathered}
$$

In practice, because environmental temperature varies more rapidly than skin temperature, this acts like a system servo controlled to environmental temperature. The set point was initially chosen so that the skin temperature was near $36^{\circ}$ (all temperatures given in degrees centigrade). The set point is then automatically raised by $0.01 \% \mathrm{~min}$ if the skin temperature is $<35.5^{\circ}$, and lowered by $0.01^{\circ} / \mathrm{min}$ if the skin temperature is $>36^{\circ}$. The regulating top wall probe (to contrast the measuring top wall probe used in making the temperature measurements reported in the results section) was placed outside the incubator, near the Merco warmer, to further decrease temperature fluctuations. The use of the computer controller, with the regulating top wall probe placed outside the incubator, produced a system with $<0.2^{\circ}$ change in environmental temperature during cycling. The convectively heated incubator was also an Air Shields Model C-86, and was also computer controlled by the same equations; however, the regulating top wall probe was placed inside the incubator and the incubator's convective heater was used rather than the Merco warmer. This system also had $<0.2^{\circ}$ change in environmental temperature during cycling.

Both warming systems were set to maintain the temperature of the same skin probe near $36^{\circ}$. A skin temperature of $36^{\circ}$ was chosen, as this was the temperature used in the clinical studies on incubator efficacy $(4,7,17)$ and the associated studies on thermal neutral environment (21). Both incubators were set to provide maximal humidity.

Oxygen consumption and respiratory quotient were measured with a Kipp-Noyon diaferometer model MG4 and recorded on a Kipp and Zonen BD-2 Micrograph. The diaferometer uses an open flow method for measuring oxygen consumption. Basically, this entails sucking air from the hood over the infant's head at such a rate that all expired gases are collected in the flow. Oxygen consumption is then calculated by multiplying the flow rate by the change in oxygen concentration relative to room air. The oxygen concentration of gas sample after $\mathrm{CO}_{2}$ and $\mathrm{H}_{2} \mathrm{O}$ are removed is proportional to its thermal conductivity, provided the relative proportions of the other constituents do not change. The diaferometer compares the concentration of oxygen in room air and expired gas in identical thermal conductivity cells and generates an electrical signal proportional to the change in oxygen concentration [more complete discussions are available in the literature $(10,16,23,24)]$. Carbon dioxide production is measured in a similar manner. The diaferometer was calibrated as described previously (12). All oxygen consumption measurements were corrected to standard temperature and pressure.

Expired gas was collected in a small polyethylene hood secured with a draw string about the infant's neck (12). The hood was constructed by stretching a polyethylene film over an aluminum frame [polyethylene is essentially transparent to thermal radiation in the infrared region (12)].

Out of concern that elevated breath hydrogen levels $(14,19)$ reported in premature babies might affect the measurement of oxygen consumption by diaferometer (24), hydrogen absorbers (Matheson Scientific, \#64-1000, decreases hydrogen concentration to $<1 \mathrm{ppm}$ ) were added to the sample and control circuit for the last three infants studied. The oxygen consumption measurements in these three babies were similar to those of the group as a whole. Respiratory quotient is a sensitive measure of hydrogen contamination because hydrogen decreases the measured oxygen consumption 10 times as much as the measured carbon dioxide production. Respiratory quotients in the total group of infants were similar to those reported by other methods for infants of similar age and weight (5). The highest respiratory quotient was measured with the hydrogen absorbers in place; thus, it is unlikely that hydrogen excretion affected the measurement of oxygen consumption in this study.

The temperatures of all six incubator walls, incubator air, hood air (temperature within the polyethylene hood used to collect expired gases), rectal, facial, and skin temperature were measured with Yellow Springs Instruments series 402 thermistors, as described previously (12). Reported temperatures are those taken at the time the oxygen consumption measurement was taken. The baby was studied naked and was placed on his stomach with his head toward the air exhaust of the incubator.

Eight of the temperatures were recorded on a strip chart. This allowed easy assessment of the thermal stability of the warming system. Air and wall temperatures were stable for at least $30 \mathrm{~min}$ before measuring oxygen consumption. Rectal and skin temperature changed no more than $0.1^{\circ}$ in the $20 \mathrm{~min}$ before measuring oxygen consumption.

It is naive to assume that the skin temperature of the entire epidermis of an infant is accurately reflected by three skin probes (18) (i.e., skin, face, foot). Mean skin temperature $\left(T_{s m}\right)$ was calculated as described previously (12):

$$
\begin{aligned}
\mathrm{T}_{\text {sm }}=0.22 \mathrm{~T}_{\text {face }} & +0.16 \mathrm{~T}_{\text {chest }}+0.16 \mathrm{~T}_{\text {back }} \\
& +0.145 \mathrm{~T}_{\text {thigh }}+0.145 \mathrm{~T}_{\text {foot }}+0.17 \mathrm{~T}_{\text {arm }}
\end{aligned}
$$

Environmental temperature $\left(\mathrm{T}_{\mathrm{env}}\right)$ was calculated

$$
\begin{aligned}
& \mathrm{T}_{\text {env }}=0.64 \mathrm{~T}_{\text {air }}+0.01 \mathrm{~T}_{\text {rew }}+0.01 \mathrm{~T}_{\text {few }}+0.06 \mathrm{~T}_{\text {fw }} \\
& +0.08 \mathrm{~T}_{\mathrm{rw}}+0.08 \mathrm{~T}_{\mathrm{dw}}+0.07 \mathrm{~T}_{\mathrm{tw}}+0.05 \mathrm{~T}_{\mathrm{sm}}
\end{aligned}
$$

$\mathrm{T}_{\text {few }}=$ front end wall temperature (the wall nearest the heater output)

$\mathrm{T}_{\text {rew }}=$ rear end wall temperature (wall nearest the air exhaust)

$\mathrm{T}_{\mathrm{fw}}=$ front wall temperature

$\mathrm{T}_{\mathrm{rw}}=$ rear wall temperature

$\mathrm{T}_{\mathrm{dw}}=$ diagonal wall temperature

$T_{t w}=$ top wall temperature

The derivation of this equation is published elsewhere (13) Metabolic rate (MR) was calculated using the oxygen consumption $\left(\mathrm{VO}_{2}\right)$ and the respiratory quotient $(\mathrm{R})$ by the equation (9), $\mathrm{MR}=\mathrm{VO}_{2} \times(1.20 \mathrm{R}+3.85)$. Radiant heat losses $\left(\mathrm{H}_{\mathrm{r}}\right)$ were calculated by the equation:

$$
\mathrm{H}_{\mathrm{r}}=\sum_{\text {walls }}\left\{(0.98) \sigma \pi^{-1} \mathrm{~A}_{\mathrm{w}} \Omega\left(\mathrm{T}_{\mathrm{sm}}-\mathrm{T}_{\text {wall }}\right)\right\}
$$

where 0.98 is the emissivity of human skin (8), the emissivity of the incubator is assumed to be 1 [based on the incubator being large relative to the infant (20)], $\sigma$ is the Stephan Boltzman 
constant, $A_{w}$ is the area of the baby projected in the plane of the wall (i.e., the amount of the baby that faces the wall), and $\Omega$ is the solid angle of the wall with respect to the baby [see Appendix to (13)]. This quantity was adjusted for differences in subject surface area [surface area was assumed proportional to weight to the 0.75 power (11)]. Percentage radiant heat losses were calculated by dividing radiant heat losses by metabolic rate.

Relative humidity was measured with a wet bulb - dry bulb thermometer placed near the infant. The statistical significance of differences was calculated using two-tailed paired $t$ test. All measurements are reported as mean \pm standard error unless otherwise stated.

\section{RESULTS}

The results are summarized in Table 2. The mean oxygen consumption by infants was $7.12 \mathrm{ml} \cdot \mathrm{kg}^{-1} \cdot \mathrm{min}^{-1}$ in the radiantly heated incubator and $7.17 \mathrm{ml} \cdot \mathrm{kg}^{-1} \cdot \mathrm{min}^{-1}$ in the convectively heated incubator. The oxygen consumption in the convectively heated incubator was greater by $0.5 \pm 0.29 \mathrm{ml} \cdot \mathrm{kg}^{-1} \cdot \mathrm{min}^{-1}$ which is not significant. The $95 \%$ confidence interval for the difference is $\left(0.68 \mathrm{ml} \cdot \mathrm{kg}^{-1} \cdot \mathrm{min}^{-1},-0.56 \mathrm{ml} \cdot \mathrm{kg}^{-1} \cdot \mathrm{min}^{-1}\right)$ or $(9 \%,-8 \%)$. Respiratory quotient, time in incubator before measurement, time since fed, and rectal, face, skin, foot, hood air, mean skin temperature, and environmental temperature were similar in the two incubator systems. Incubator air temperature was $1.8 \pm 0.2^{\circ}$ colder $(P<0.001)$ and relative humidity was $5.2 \pm 2.1 \%$ lower in the radiantly heated incubator $(P<0.05)$.

Metabolic rate correlated significantly with environmental temperature $(r=-0.61, P<0.0005)$, and more strongly with environmental skin gradient $\left(\mathrm{T}_{\mathrm{sm}}-\mathrm{T}_{\mathrm{env}}, r=0.65, P<0.0001\right.$, Fig. 1). The correlations of metabolic rate with air temperature $(r=-0.41, P<0.05)$ and with air skin gradient $(r=0.41, P<$ 0.02 ) were weaker though not significantly so. The correlation of environmental temperature with metabolic rate is an indication that in devices controlled in the neutral thermal zone differences in basal metabolic rate or heat production will be reflected in differences in environmental skin gradient or heat loss. That the correlation is not an indication that the babies were controlled in a subneutral thermal zone is shown in Table 3 . If the babies were controlled in a subneutral thermal zone, those infants who had lower environmental temperatures in convective incubators would have higher metabolic rates in that incubator. The same would be true for the radiant incubator; thus, there would be a significant excess of infants in the radiant, radiant, and convective, convective blocks of the table. No significant excess was seen. Metabolic rate did not correlate with skin temperature $(r=0.06)$ or mean skin temperature $(r=0.00)$.

The percentage of total heat loss accountable by radiant losses ( $\%$ heat loss radiant) was less in the radiantly heated incubator $(40 \pm 5 \%$ less, $P<0.001)$. The calculated $\%$ heat loss radiant in the convective incubator was $68 \%$. Evaporative losses in 3-wk-

Fig. I

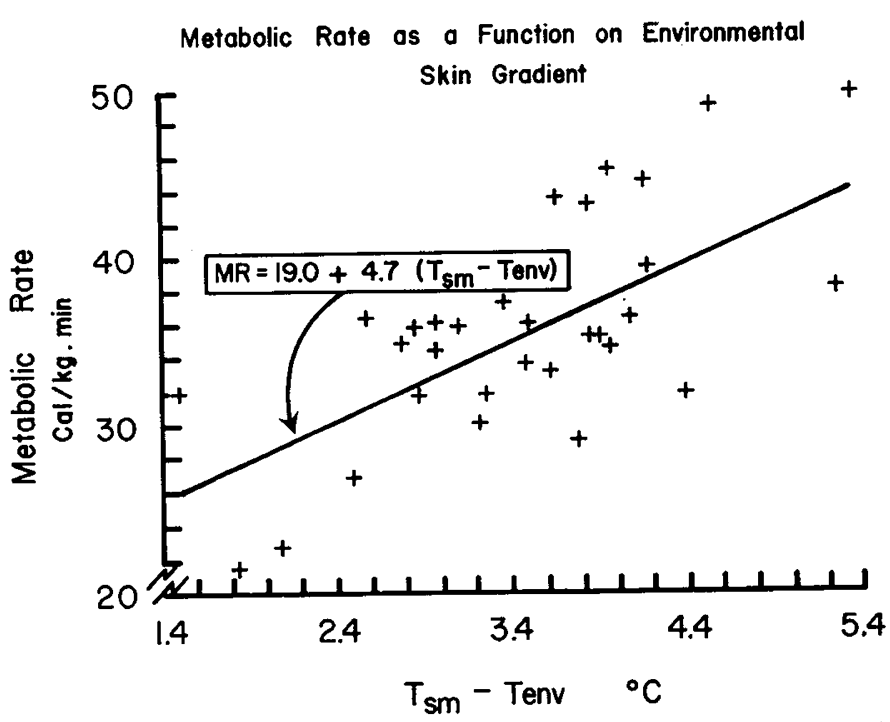

Fig. 1. The relationship between metabolic rate and environmental skin temperature gradient found in this study $(r=0.64, P<0.0001)$.

Table 3. Distribution of infants by the incubator in which the lowest environmental temperature $\left(T_{\text {cnv }}\right)$ and the highest metabolic rate (MR) was recorded

\begin{tabular}{llcc} 
& & \multicolumn{2}{c}{ Highest MR } \\
\cline { 3 - 4 } & & Convective & Radiant \\
\hline Lowest & Convective & 5 & 3 \\
$\mathrm{~T}_{\text {env }}$ & Radiant & 4 & 4 \\
\hline
\end{tabular}

Table 2. Measurements in the convectively heated incubator and the radiantly heated incubator*

\begin{tabular}{|c|c|c|c|c|}
\hline & $\mathrm{Cl}$ & RI & $(\mathrm{CI}-\mathrm{RI})+\mathrm{SE}$ & $P$ \\
\hline $\mathrm{O}_{2}$ & $7.17 \pm 0.35$ & $7.12 \pm 0.3$ & $.05 \pm 0.3$ & NS \\
\hline $\mathrm{RQ}$ & $0.95 \pm 0.03$ & $0.99 \pm 0.03$ & $-.04 \pm 0.03$ & NS \\
\hline Time in inc. & $108 \pm 19$ & $139 \pm 19$ & $-31 \pm 26$ & NS \\
\hline Time since fed & $80 \pm 10$ & $85 \pm 10$ & $-5 \pm 14$ & NS \\
\hline Rectal temp & $36.67 \pm 0.08$ & $36.66 \pm 0.07$ & $.01 \pm 0.08$ & NS \\
\hline Facial temp & $35.9 \pm 0.1$ & $36.0 \pm 0.1$ & $-0.1 \pm 0.1$ & NS \\
\hline Skin temp & $35.93 \pm 0.04$ & $35.93 \pm 0.5$ & $.006 \pm 0.06$ & NS \\
\hline Foot temp & $34.0 \pm 0.3$ & $33.5 \pm 0.4$ & $0.5 \pm 0.4$ & NS \\
\hline Hood temp & $32.8 \pm 0.2$ & $32.7 \pm 0.2$ & $0.1 \pm 0.2$ & NS \\
\hline Air temp & $32.9 \pm 0.3$ & $31.1 \pm 0.1$ & $1.8 \pm 0.2$ & $P<0.001$ \\
\hline Humidity & $76 \pm 1 \%$ & $71 \pm 2 \%$ & $5.2 \pm 2.1 \%$ & $P<0.05$ \\
\hline $\mathrm{T}_{\mathrm{sm}}$ & $35.5 \pm 0.1$ & $35.5 \pm 0.1$ & $-.04 \pm 0.10$ & NS \\
\hline $\mathrm{T}_{\mathrm{env}}$ & $32.1 \pm 0.3$ & $32.0 \pm 0.2$ & $0.1 \pm 0.1$ & NS \\
\hline Metabolic rate & $35.5 \pm 1.6$ & $35.4 \pm 1.6$ & $0.1 \pm 1.2$ & NS \\
\hline$\%$ Heat loss radiant & $68 \pm 3 \%$ & $28 \pm 5 \%$ & $40 \pm 5 \%$ & $P<0.001$ \\
\hline
\end{tabular}

* The oxygen consumption in $\mathrm{ml} \cdot \mathrm{kg}^{-1} \cdot \mathrm{min}^{-1}$, respiratory quotient (RQ), total time in incubator system (time in inc.), time since last feeding (time since fed) in min, various temperatures in ${ }^{\circ} \mathrm{C}$, relative humidity, metabolic rate in cal $\cdot \mathrm{kg}^{-1} \cdot \mathrm{min}^{-1}$ and percentage of metabolic rate accountable by radiant heat losses (\% heat loss radiant), are given in the convectively heated incubator $(\mathrm{CI})$ and the radiantly heated incubator (RI) with standard errors. Because this is paired data, the third column shows the differences found (convectively heated-radiantly heated) $\pm \mathrm{SE}$ of the difference. The last column shows the significance level (NS is not significant, $P>0.1$ ). 
old infants at the humidities used in this study would be very small $(15,22)$. Therefore, $\%$ heat loss radiant corresponds to the percentage of non-evaporative heat losses accountable by radiant losses reported by others $(9,25,26)$.

\section{DISCUSSION}

No significant difference was found in the degree to which a radiantly heated incubator and a convectively heated incubator as used in this experiment could approximate a neutral thermal environment in the small premature. Although this experiment would have detected an $8-9 \%$ difference in oxygen consumption, a smaller difference might not have been picked up [i.e., the $95 \%$ confidence interval is $(9 \%,-8 \%)]$. The fact that the mean difference was $<1 \%$ is somewhat reassuring and indicates that in a short-term experiment in stable enclosed incubators there is no detectable advantage to convective or radiant energy.

It should be mentioned that different methods of assessing the thermal cost of a warming system could be used. The use of nonREM sleep is arbitrary, and other quiet states could have been chosen. Indeed, one could choose to average oxygen consumption over all states to produce a total metabolic expenditure. If the efficacy of warmer incubators $(4,7,17)$ is caused by reducing metabolic expenditure, this would theoretically be the best method of assessing incubator efficacy. This method, however, is not a measure of thermoneutrality, which requires a quiet state for measurement. Although it is possible that any of these choices could have produced different results, it is likely there would be a high degree of correlation between the results of all these methods $(3,6)$.

The lack of a difference in oxygen consumption of infants in radiantly and convectively heated incubators, contrasts the demonstrable difference in the relative thermoneutrality of an open radiant warmer and a convectively heated incubator $(12,26)$. The relative inferiority of the thermal environment produced by an open radiant warmer, therefore, is not due solely to the use of radiant energy as a heat source. The $\%$ heat loss radiant reported here for the convective incubators is similar to the \% non-evaporative heat loss radiant reported by Wheldon and Rutter $(25,26)$ and the earlier estimate of Hey and Mount (9).

\section{REFERENCES AND NOTES}

1. Atherton, H. D., Edwards, N. K., and Peristein, P. H.: Temperature controlling methods and apparatus for incubators. U. S. Patent \#3920000

2. Bligh, J. and Johnson, K. G. Glossary of terms for thermat Appl. Physiol. 35.941. G.: Glossary of terms for thermal physiology. J. Appl. Physiol., 35: 941 (1973).

3. Brück, K., Parmelee Jr., A. H., and Brück, M.: Neutral temperature range and range of "thermal comfort" in premature infants. Biol. Neonat., 4: 32 (1962)

4. Buetow, K. C. and Klein, S. W.: Effect of maintenance of "normal" skin temperature on survival of infants of low birth weight. Pediatrics, $34: 163$
5. Darnall, R. A. and Ariagno, R. L.: Minimal oxygen consumption in infants cared for under overhead radiant warmers compared with conventional incubators. J. Pediatrics, 93: 283 (1978).

6. Darnall, R. A. and Ariagno, R. L.: The effect of sleep state on active thermoregulation in the premature infants. Pediatr. Res., 16:512 (1982).

7. Day, R. L., Caliguiri, L., Kamenski, C., and Ehrilich, F.: Body temperature and survival of premature infants. Pediatrics, 34: 171 (1964).

8. Hardy, J. D.: The radiating power of human skin in the infrared. Am. J. Physiol., 127: 454 (1939).

9. Hey, E. N. and Mount, L. E.: Heat losses from babies in incubators. Arch. Dis Child., 2: 75 (1967).

10. Karlberg, P.: Determination of standard energy metabolism (basal metabolism) in normal infants. Acta Paediatr. (suppl.), 89:41 (1952).

11. Klein, A. D. and Scamman, R. E.: Relations between surface area, weight, and length of the human body in prenatal life. Proc. Exp. Biol. Med., 27: 456 (1929).

12. LeBlanc. M. H.: The relative efficacy of an incubator and an open warmer in producing thermoneutrality in small premature. Pediatrics, $69 \cdot 439(1982)$

13. LeBlanc, M. H.: Oxygen consumption in premature infants in an incubator of proven clinical efficacy. Biol. Neonate, 44: 76 (1983).

14. Maclean, W. C. and Fink, B. B.: Lactose malabsorption by premature infants: magnitude and clinical significance. J. Pediatr., 97: 383 (1980).

15. Needleman, H., Lorenz, J., and Perlstein, P. H.: Phototherapy effect on insensible weight loss in humid environment. Pediatr. Res., 15:674 (1981).

16. Noyons, A. K. M.: Methode d'enregistrement continu de la teneur en $\mathrm{CO}_{2}$ et en $\mathrm{O}_{2}$ des gaz respiratoires au moyen du metabolisme des tissus des animaux et de l'homme. Ann. Physiol. Physiochi. Biol., 13: 909 (1937).

17. Perlstein, P. H., Edwards, N. K., and Atherton, H. D.: Computer-assisted newborn intensive care. Pediatrics, 57: 494 (1976).

18. Perlstein, P. H., Edwards, N. K., and Sutherland, J. M.: Age relationships to thermal patterns on the backs of cold-stressed infants. Biol. Neonat., 20:127 (1972).

19. Perman, J. A., Barr, R. G., and Watkins, J. B.: Sucrose malabsorption in children: non-invasive diagnosis by interval breath hydrogen determination. J. Pediatr., 93: 17 (1978).

20. Sears, F. W. and Zemansky, M. W.: University Physics, 3rd ed., p. 384 (Addision-Wesley Publishing Co., Reading, MA 1964).

21. Silverman, W. A., Sinclair, J. A., and Agate, F. J.: The oxygen cost of minor changes in heat balance of small newborn infants. Acta Paediatr. Scand., 55: 294 (1966).

22. Sulyok, E., Jequier, E., and Tyser, G.: Effect of relative humidity on thermal balance of the newborn infant. Biol. Neonat., 21: 210 (1972).

23. Ten Hoor, E., Rispens, P., Van de Walle, and Zijlstra, W. G.: Determination of oxygen uptake and carbon dioxide production in animals and man using a diaferometer calibrated with expired gas. Application in the direct Fick procedure for determining cardiac outputs. K. Ned. Akad, Wet., Ser. C., 77: 429 (1974).

24. Visser, B. F.: Clinical gas analysis based on thermal conductivity. (Thesis, Utrecht. 1975).

25. Wheldon, A. E.: Energy balance in the newborn baby: use of a manikin to estimate radiant and convective heat loss. Phys. Med. Biol., 27: 285 (1982)

26. Wheldon, A. E. and Rutter, N.: The heat balance of small babies nursed in incubators and under radiant warmers. Early Hum. Devel., 6: 161 (1982).

27. Requests for reprints should be addressed to: Dr. Michael H. LeBlanc, Department of Pediatrics, Newborn Division, University of Mississippi, College of Medicine, 2500 North State Street, Jackson, Mississippi, 39216.

28. This research was supported by Department of Health and Human ServicesUnited States Public Health Service Grant MCT-000174, National Institutes of Health Grant HD 07200 and Division of Research Resources Clinfo Grant \#RR00068-18-52 General Clinical Research Center.

29. Received for publication February 16, 1983

30. Accepted for publication July 13,1983. 